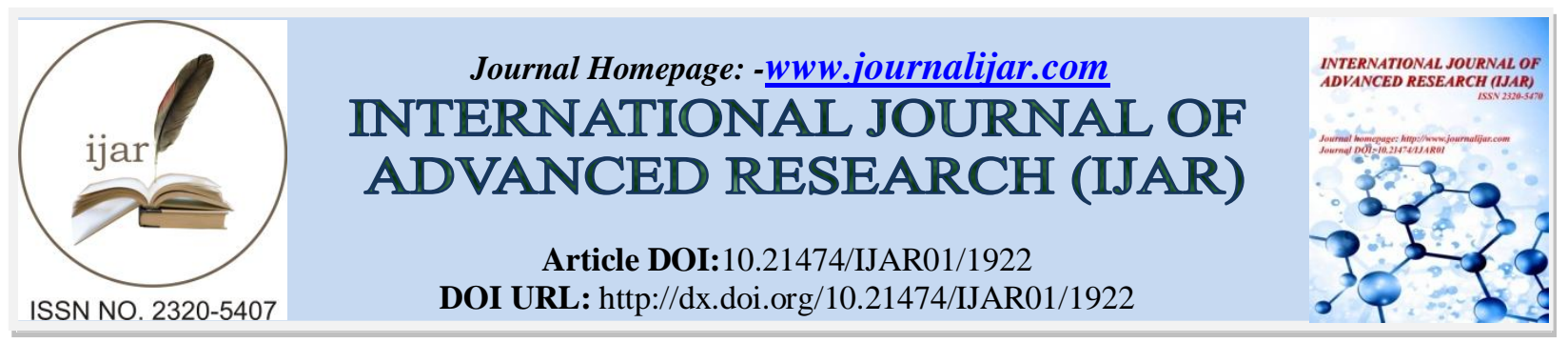

RESEARCH ARTICLE

\title{
EFFECT OF INSECTICIDES ON SOIL MICROBIAL RESPIRATION.
}

1. Hislop College, Nagpur, India.

2. Shivaji Science College, Nagpur, India.

3. Hislop College, Nagpur, India.

\section{Manuscript Info} (.........................

Manuscript History

Received: 12 August 2016

Final Accepted: 16 September 2016

Published: October 2016

Key words:-

Soil microbial respiration, insecticide fortification, $\mathrm{CO}_{2}$ evolution.

\section{Abstract}

Laboratory experiment was conducted to study the effect of chlorpyrifos and cypermethrin insecticides on soil microbial respiration. In the experiment replicated trials were conducted on experimental field soil before application of selected insecticides using chlorpyrifos 20EC and cypermethrin 25EC at 0, 5, 10, 15, 20, 50 and 100ppm levels of fortification. The heterotrophic activities of soil micro-organisms were measured in terms of $\mathrm{CO}_{2}$ evolved after incubation period spanning from 5, 20, 35 and 50 days. The results obtained in the experiment revealed that both chlorpyrifos and cypermethrin showed gradual decrease in $\mathrm{CO}_{2}$ evolution for all levels of fortification as compare to untreated soil. But there was no adverse effect on soil microbial activity.

Copy Right, IJAR, 2016,. All rights reserved.

\section{Introduction:-}

Pesticides are toxic agrochemicals used frequently in the field to increase crop yields by controlling insect pest infestation. Thus pesticides have become an integral part of modern agriculture. Modern agriculture worldwide uses a variety of pesticides including insecticides, nematicides, herbicides and fungicides to optimize crop production (Lo 'pez et al., 2002; Cycon et al., 2006). Pesticides when applied on crop as foliar spray, they fall on soil and affect the population and activity of beneficial microorganisms in soil as well as physico- chemical properties of soil. (Pandey \& Singh, 2004) When pesticides are used in crop protection, the possibilities of these chemicals may exert certain effect on non target organisms along with targeted organisms. Microorganisms make up less than $1 \%$ of total soil volume (Purohit, 2003) and they are categorized into bacteria, actinomycetes, fungi, algae and protozoa (Rao, 1995). One of the main activities of these soil microorganisms is the decomposition of organic matter in the soil. Synthetic insecticides are generally organic compounds and microorganisms are able to break down these compounds by their enzymes and utilize carbon as a source of energy (Purohit 2003). Therefore, soil respiration is a good index to evaluate the activity of microorganisms involved in organic matter decomposition. (Komal et al., 1999) To evaluate toxic effect exerted by insecticides on soil microorganisms, soil respiration index is frequently used. (W. J. Jones \& N.D. Ananyeva, 2001 \& A.Kalia \& S.K. Gosal, 2011)

The impact of insecticides on various soil parameters, including soil microbial respiration has been studied by many workers. (D.Sengupta et al., 2009, A.C. Das et al., 1995, Digrak M. and F. Kazanici, 2001) There are many results regarding favorable as well as adverse effects of insecticides on growth and activities of microorganisms in the soil. (S.Bhuyan et al., 1992, Bujin X.U. and Z. Yongxi, 2000) but these effects on soil microbial activities are temporary. Also, the effects of different insecticides on the growth and activities of micro-organisms in the soil show variations as different groups of insecticides exhibit variations in toxicity. (Das A. C. and D. Mukherjee, 2000) In the present 
study investigations on effect of selected insecticides, namely cypermethrin and chlorpyrifos under controlled laboratory conditions on soil from the agricultural experimental farm in Nagpur, India has been undertaken.

\section{Materials and Method:- \\ Materials:-}

Soil from experimental field, cypermethrin 25EC, chlorpyrifos 20EC, barium chloride $(\mathrm{BaCl} 2), \mathrm{NaOH}, \mathrm{HCl}$, phenolphthalein indicator, conical flasks $(500 \mathrm{ml})$, glass vials $(25 \mathrm{ml})$, rubber corks with hook, burette, conical flask(250ml).

\section{Method:-}

Preparation of incubation chamber:-

Incubation chamber was prepared using $500 \mathrm{ml}$. conical flask which was tightly fitted with rubber cork. The rubber cork was provided with a hook in order to suspend $25 \mathrm{ml}$ glass tube inside the conical flask with the help of thread during experimentation.

\section{Soil treatment with pesticides cypermethrin and chlorpyrifos:-}

In incubation chamber $50 \mathrm{gm}$ soil was taken which was mixed with appropriate quantity of water in order to maintain field condition. Soil was then mixed with $10 \mathrm{ml}$ of cypermethrin insecticide suspensions prepared in water of different concentration i.e. $0 \mathrm{ppm}, 5 \mathrm{ppm}, 10 \mathrm{ppm}, 15 \mathrm{ppm}, 20 \mathrm{ppm}, 50 \mathrm{ppm}$ and $100 \mathrm{ppm}$. Then glass tube (25ml) filled with $10 \mathrm{ml}$ of $0.5 \mathrm{~N} \mathrm{NaOH}$ was kept suspended in each incubation chamber with the help of thread hooked from the cork inside the chamber. Rubber stopper was fitted tightly.

Similarly incubation chamber with $50 \mathrm{gm}$ soil were taken which were mixed with appropriate quantity of water in order to maintain field condition and then was mixed with $10 \mathrm{ml}$ of chlorpyrifos insecticide suspensions, prepared in water of different concentration i.e. $0 \mathrm{ppm}, 5 \mathrm{ppm}, 10 \mathrm{ppm}, 15 \mathrm{ppm}, 20 \mathrm{ppm}, 50 \mathrm{ppm}$ and $100 \mathrm{ppm}$. Then glass tube (25ml) filled with $10 \mathrm{ml}$ of $0.5 \mathrm{~N} \mathrm{NaOH}$ was kept suspended in each incubation chamber with the help of thread hooked from the cork inside the chamber. Rubber stopper was fitted tightly.

\section{Incubation of soil with pesticides cypermethrin and chlorpyrifos:-}

Effect of cypermethrin and chlorpyrifos insecticides on soil micro flora was evaluated by fortification of soil at $0,5,10,15,20,50$ and $100 \mathrm{ppm}$ using three replicated sets. Observations were recorded at an interval of 5days, 20 days, 35 days and 50 days in terms of $\mathrm{CO}_{2}$ evolved in the incubation chamber.

\section{Method of recording observations:-}

The glass tube in the chamber was taken out at 5,20,35 and 50 days from the start of experiment. Every time content of the glass tube was used for titration and the glass tube was replaced immediately with fresh vial containing the $10 \mathrm{ml}$ of $0.5 \mathrm{~N} \mathrm{NaOH}$. The content of the vial was titrated with $0.7 \mathrm{~N} \mathrm{HCl}$ using $10 \mathrm{ml}$ of $1 \mathrm{~N} \mathrm{BaCl}_{2}$ and phenolphthalein indicator.

The amount of $\mathrm{CO}_{2}$ evolved from the soil was calculated by formula given below:

$$
\mathrm{CO}_{2} \text { evolved }(\mathrm{mg} / \mathrm{g} \text { soil })=\frac{(B-A) \times 2.2}{0.1 \times N / 50}
$$

Where,

$\mathrm{A}=\mathrm{ml}$ of $0.7 \mathrm{NHCl}$ required to neutralize $\mathrm{NaOH}$ in the vial from incubation chamber.

$\mathrm{B}=\mathrm{ml}$ of $0.7 \mathrm{NHCl}$ required for blank reading.

$\mathrm{N}=$ Normality of acid used $\left(1 \mathrm{ml}\right.$ of $0.1 \mathrm{NHCl}$ is equivalent to $\left.2.2 \mathrm{mg} \mathrm{CO}_{2}\right)$ ]

The calculated quantity of $\mathrm{CO}_{2}$ per gram soil from four observations for the incubation period of 5days, 20 days, 35 days and 50 days were considered together and used for comparison. Following photographs show assembly prepared and used during recording observations. 


\section{Result:-}

Carbon dioxide liberated from the soil in incubation chamber was trapped in $\mathrm{NaOH}$ solution and by titration with standard acid $(\mathrm{HCl})$; the quantity of $\mathrm{CO}_{2}$ was calculated in $\mathrm{mg} / \mathrm{g}$ soil for the total incubation period of 50 days. The soil for the experiment was collected from experimental farm and was fortified with cypermethrin and chlorpyrifos at the level of $0,5,10,15,20,50$ and $100 \mathrm{ppm}$ using the calculated quantity of formulated emulsifiable concentrate. Initially the $\mathrm{CO}_{2}$ was measured after 5days of fortification and subsequently it was measured at an interval of 15 days (readings correspond to 20days of incubation period), 30days (readings correspond to 35days of incubation period) and 45 days (readings correspond to 50days of incubation period). The total quantity of carbon dioxide liberated in all four observations was taken for comparison.

Effect of pesticides, cypermethrin on soil microbial respiration:-

The quantity of $\mathrm{CO}_{2}$ liberated $(\mathrm{mg} / \mathrm{g}$ soil) from incubated soil with cypermethrin in incubation chamber at various levels of fortification and at different incubation period is presented in Table 1.

Table 1:- Influence of Cypermethrin (25EC) on $\mathrm{CO}_{2}$ evolution from soil (incubation period from 5days to 50days)

\begin{tabular}{|c|c|c|c|c|}
\hline \multicolumn{5}{|c|}{ Influence of Cypermethrin 25EC on soil respiration } \\
\hline \multirow{2}{*}{$\begin{array}{ll}\text { Level } & \text { of } \\
\text { fortification } & \text { in } \\
(\mathrm{ppm}) & \end{array}$} & \multicolumn{4}{|c|}{$\mathrm{CO}_{2}$ evolved in $\mathrm{mg} / \mathrm{g}$ soil } \\
\hline & 5 Days & 20 Days & 35Days & 50Days \\
\hline 0 & $3.63( \pm 0.16)$ & $2.6( \pm 0.0836)$ & $1.86( \pm 0.1645)$ & $0.96( \pm 0.1474)$ \\
\hline 5 & $3.5( \pm 0.08)$ & $2.5( \pm 0.0816)$ & $1.8( \pm 0.0816)$ & $0.95( \pm 0.0408)$ \\
\hline 10 & $3.5( \pm 0.08)$ & $2.47( \pm 0.0471)$ & $1.76( \pm 0.3522)$ & $0.93( \pm 0.0918)$ \\
\hline 15 & $3.4( \pm 0.00)$ & $2.45( \pm 0.08167)$ & $1.75( \pm 0.040)$ & $0.86( \pm 0.2318)$ \\
\hline 20 & $3.4( \pm 0.086)$ & $2.42( \pm 0.02449)$ & $1.73( \pm 0.1173)$ & $0.86( \pm 0.1428)$ \\
\hline 50 & $3.36( \pm 0.216)$ & $2.38( \pm 0.1405)$ & $1.6( \pm 0.405)$ & $0.73( \pm 0.0936)$ \\
\hline 100 & $3.3( \pm 0.816)$ & $2.33( \pm 0.133)$ & $1.0( \pm 0.416)$ & $0.56( \pm 0.098)$ \\
\hline
\end{tabular}

In untreated soil (0ppm level of fortification) the $\mathrm{CO}_{2}$ evolved showed gradual decreasing trend from 5 days to 50 days of incubation period. The amount of $\mathrm{CO}_{2}$ evolved was $3.63 \mathrm{mg} / \mathrm{g}, 2.6 \mathrm{mg} / \mathrm{g}, 1.0 \mathrm{mg} / \mathrm{g}$ and $0.56 \mathrm{mg} / \mathrm{g}$ for $5,20,35$ and 50days respectively.

Whereas in case of soil with 5, 10, 15 and 20ppm fortification level of cypermethrin, the amount of $\mathrm{CO}_{2}$ evolved also showed gradual decrease during 5 days to 50 days which was in the range of 3.5 to $3.4 . \mathrm{mg} / \mathrm{g}$ to $0.95 \mathrm{to} 0.86 \mathrm{mg} / \mathrm{g}$. which when compared with untreated soil was at par.

However, relatively more reduction in $\mathrm{CO}_{2}$ evolved was noticed as compare to untreated soil (0ppm level of fortification) at 50 and $100 \mathrm{ppm}$ fortification level of cypermethrin during 5days to 20days and $\mathrm{CO}_{2}$ quantity recorded was 3.36 to $3.3 \mathrm{mg} / \mathrm{g}$ and 2.38 to $2.33 \mathrm{mg} / \mathrm{g}$ soil, respectively. Also, after 35 days of incubation period, the same trend was found i.e. as compare to untreated soil the $\mathrm{CO}_{2}$ evolved showed gradual decrease with increasing level of fortification. For 35 days of incubation period quantity of $\mathrm{CO}_{2}$ recorded for untreated soil was $1.86 \mathrm{mg} / \mathrm{g}$ whereas, for increasing levels of fortification from 5 to $100 \mathrm{ppm}$, it was recorded as $1.8,1.76,1.75,1.73,1.6$ and 1.0 $\mathrm{mg} / \mathrm{g}$, respectively. This decreasing trend in $\mathrm{CO}_{2}$ evolution was observed till 50 days of incubation period. The quantity of $\mathrm{CO}_{2}$ evolved for untreated soil after 50 days was $0.96 \mathrm{mg} / \mathrm{g}$ and for soil incubated with increasing levels of fortification from 5 to $100 \mathrm{ppm}$, it was $0.95,0.93,0.86,0.86,0.73 \mathrm{and} 0.56 \mathrm{mg} / \mathrm{g}$, respectively.

\section{Effect of chlorpyrifos on soil microbial respiration:-}

In the laboratory experiment performed on farm soil, the quantity of $\mathrm{CO}_{2}$ liberated (mg/g soil) from incubated soil with chlorpyrifos in incubation chamber at various levels of fortification and at different incubation period is presented in Table 2. 
Table 2:- Influence of Chlorpyrifos (20EC) on $\mathrm{CO}_{2}$ (For incubation period from 5days to 50days).

\begin{tabular}{|c|c|c|c|c|}
\hline \multicolumn{5}{|c|}{ Influence of Chlorpyrifos 20EC on soil respiration } \\
\hline \multirow{2}{*}{$\begin{array}{ll}\text { Level } & \text { of } \\
\text { fortification in } \\
(\mathrm{ppm})\end{array}$} & \multicolumn{4}{|c|}{$\mathrm{CO}_{2}$ evolved in $\mathrm{mg} / \mathrm{g}$ soil } \\
\hline & 5 Days & 20 Days & 35Days & 50Days \\
\hline 0 & $3.65( \pm 0.0816)$ & $3.51( \pm 0.2174)$ & $3.28( \pm 0.01414)$ & $3.19( \pm 0.1632)$ \\
\hline 5 & $3.58( \pm 0.1582)$ & $3.48( \pm 0.01414)$ & $3.25( \pm 0.01632)$ & $3.15( \pm 0.0816)$ \\
\hline 10 & $3.46( \pm 0.0816)$ & $3.42( \pm 0.0216)$ & $3.21( \pm 0.08164)$ & $3.10( \pm 0.0216)$ \\
\hline 15 & $3.41( \pm 0.1517)$ & $3.38( \pm 0.0294)$ & $\left.3.19^{ \pm 0.0216}\right)$ & $3.07( \pm 0.01414)$ \\
\hline 20 & $3.35( \pm 0.0163)$ & $3.21( \pm 0.0496)$ & $3.08( \pm 0.0216)$ & $2.92( \pm 0.0816)$ \\
\hline 50 & $3.26( \pm 0.0141)$ & $3.15( \pm 0.01414)$ & $2.87( \pm 0.01632)$ & $2.75( \pm 0.0294)$ \\
\hline 100 & $3.18( \pm 0.029)$ & $3.06( \pm 0.1267)$ & $2.55( \pm 0.0216)$ & $2.48( \pm 0.222)$ \\
\hline
\end{tabular}

The $\mathrm{CO}_{2}$ evolved from untreated soil (0ppm) for incubation period of 5 days was $3.65 \mathrm{mg} / \mathrm{g}$ which was slowly decreased after incubation period of 20 days to $3.51 \mathrm{mg} / \mathrm{kg}$ and then showed further decrease to 3.28 and $3.19 \mathrm{mg} / \mathrm{g}$ for incubation period of 35 days and 50 days, respectively.

Similar trend was observed in case of soil treated with chlorpyrifos with fortification level $5,10,15,20,50$ and 100 ppm for 5 to 50 days of incubation period. With increasing levels of fortification, the quantity of $\mathrm{CO}_{2}$ evolved was gradually decreased in the range of 3.58 to $3.18 \mathrm{mg} / \mathrm{g}$ for 5 days of incubation period. whereas for incubation period of 20 days it decreased gradually from $3.48 \mathrm{mg} / \mathrm{g}$ to $3.06 \mathrm{mg} / \mathrm{g}$. and for 35 and 50 days of incubation period the quantity of $\mathrm{CO}_{2}$ evolved were 3.28 to $2.55 \mathrm{mg} / \mathrm{g}$ and 3.19 to $2.48 \mathrm{mg} / \mathrm{g}$,respectively which shows with increasing level of fortification there was gradual decrease in $\mathrm{CO} 2$ evolved.

The quantity of $\mathrm{CO}_{2}$ evolved from untreated soil (0ppm) for incubation period of 5 to 50 days when compared with soil fortified with 5 to $100 \mathrm{ppm}$ chlorpyrifos, it was observed that there was continuous decrease in $\mathrm{CO}_{2}$ evolved in case of treated soil for 5 to 50 days and fortified with 5 to $100 \mathrm{ppm}$ chlorpyrifos.

However, relatively more reduction in $\mathrm{CO}_{2}$ evolved was noticed as compare to untreated soil (0ppm level of fortification) at 50 and $100 \mathrm{ppm}$ fortification level of chlorpyrifos during 5days to 50days and $\mathrm{CO}_{2}$ quantity recorded was 3.26 to $3.18 \mathrm{mg} / \mathrm{g}, 3.15$ to $3.06 \mathrm{mg} / \mathrm{g}, 2.87$ to $2.55 \mathrm{mg} / \mathrm{g}$ and 2.75 to $2.48 \mathrm{mg} / \mathrm{g}$ soil, respectively.

\section{Discussion:-}

When soil was treated with different fortified levels of cypermethrin, the $\mathrm{CO}_{2}$ that evolved in the incubation chamber from 5 days to 50 days indicated that there was a gradual decrease in microbial activity when compared from 5days to 50days with increasing fortification levels as seen in Table 1. However, when compared with untreated soil, the treated soil, irrespective of the concentrations of the cypermethrin mixed, showed minimal toxic or adverse effect on the soil micro-flora as seen in Fig.1. Thus, our result supported the work of M.A.Latif et al., 2008 who reported that cypermethrin had no adverse effect on soil microbes. 
Fig 1:- Graph showing influence of Cypermethrin (25EC) on $\mathrm{CO}_{2}$ evolved (For incubation period from 5days to 50days).

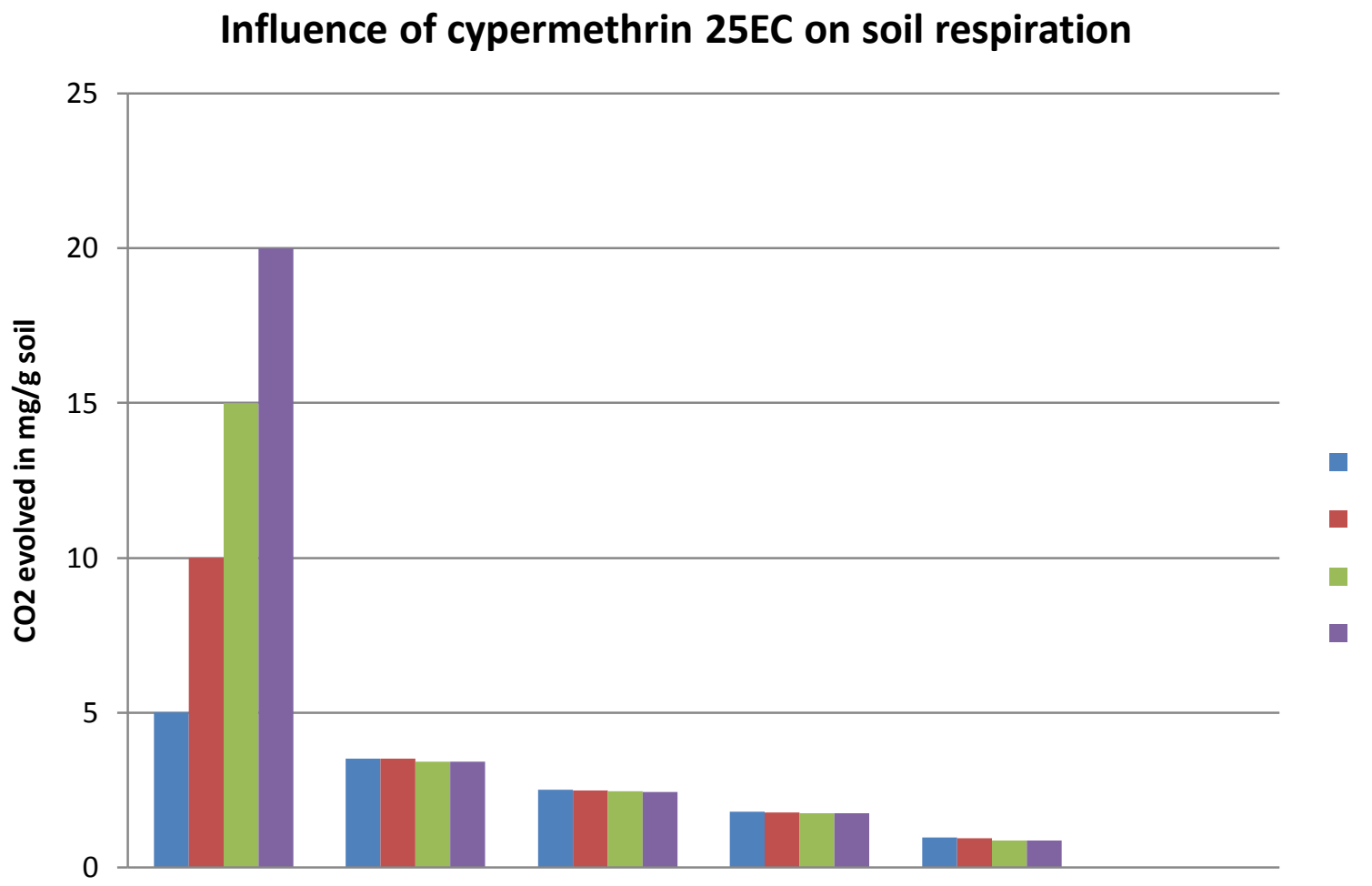

Levels of cypermethrin fortification in ppm

Similar findings were reported by Sonia Sethi and Saksham Gupta, 2013 in their comparative studies on, impact of pesticides on soil microbial biomass carbon assessed the effect of five pesticides namely cypermethrin, malathion, imidacloprid (victor), monocrotophos ( monocil) and dimethoate (tafgor) and five biopesticides on soil microbial biomass carbon under laboratory condition. All pesticides showed short lived transient toxic effect on soil microbial biomass carbon.

Moumit Roy Goswami et al., 2012 reported that application of cypermethrin insecticide on soil at their recommended dose showed short term weak transient toxic effect on soil biomass and respiration.

When soil was treated with different fortified levels of chlorpyrifos, the $\mathrm{CO}_{2}$ that evolved in the incubation chamber from 5 days to 50 days showed decrease in the $\mathrm{CO}_{2}$ evolution. This is evident in Table 2 and these results were in agreement with the results reported by Pandey and Singh (2004).

Ahmed, S. and Ahmed, M. S., 2006 and Nazia Sultan et al., 2010, reported in their study that chlorpyrifos insecticide treatments displayed a short-term inhibitory effect on microbial activity which were in agreement with the results obtained in present study and as seen in Fig.2. 
Fig 2:- Graph showing influence of Chlorpyrifos (20EC) on $\mathrm{CO}_{2}$ evolved (For incubation period from 5days to 50days)

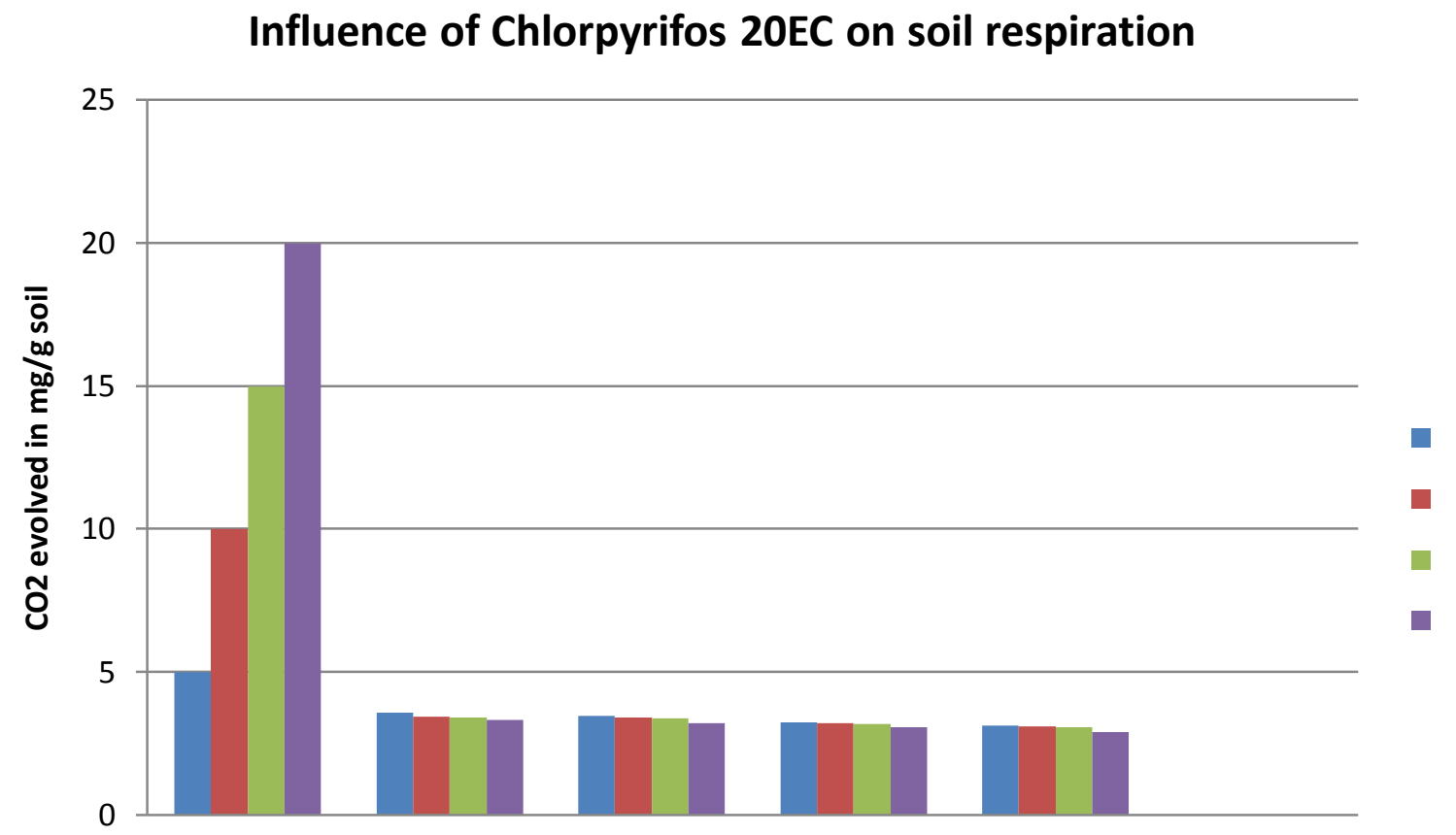

Levels of chlorpyrifos fortification (ppm)

Soil microbial activity in terms of $\mathrm{CO}_{2}$ evolved was decreased from 5 to 50 days (Table2) with slight adverse effects on microbial activity attributed by chlorpyrifos present in the soil. These observations were in agreement with the observations reported by M.A.Latif et al., 2008 who reported that chlorpyrifos had inhibitory effect on microbial respiration when observed after 24 or 32 days of incubation.

Masum Billah et al., 2014, conducted an experiment in the laboratory to know the impact of 4 selected insecticides i.e. Diazinon 60 EC, Marshal 20 EC, Dursban 20 EC and Admire 200 SL, on soil microorganisms, reported that chlorpyrifos (Dursban) $20 \mathrm{EC}$ had adverse effect on microbial activity at initial period of incubation and also reported in their studies that as compared to control there was gradual decrease in $\mathrm{CO}_{2}$ evolved for initial period of incubation. These results are in agreement with results obtained in the present findings.

S.S. Sarnaik et al., 2004, in their studies on effect of application of different pesticides to soysbean on the soil microflora, reported that chlorpyrifos had no adverse effect on soil microflora which was in agreement with the present study.

\section{Conclusion:-}

The results obtained in the present study reveal that cypermethrin $25 \mathrm{EcC}$ and chlorpyrifos $20 \mathrm{EC}$ applied on experimental farm soil had minimal inhibitory effect as compare to untreated soil for different levels of fortification of insecticides applied as well as for different days of incubation period ,on soil microbial activity.

Therefore, it may be concluded that cypermethrin and chlorpyrifos can be safely used in crop protection using appropriate concentrations so that their effects will not be harmful to soil microorganisms. 


\section{References:-}

1. A.Kalia\& S.K. Gosal,2011, Archives of Agronomy and Soil Science, 57, 569-596)

2. Ahmed, S. and Ahmed, M. S. (2006) Ahmed, S. and Ahmed, M. S. 2006. Effect of Insecticides on the total number of soil bacteria under laboratory and field conditions. Pak Entamol. 28(2):63-67.

3. Bhuyan S., S.k.Sahu, T.K. Adhya and N. Sethunathan, 1992. Accelerated aerobic degradation of hexachlorocyclohexane in suspension of flooded and non-flooded soils pre-treated with hexachlorocyclohexane. Biol. Fert. Soils, 12:279-284.

4. Bujin X.U. and Z. Yongxi, 2000.Impact of repeated insecticide application on soil microbial activity. IAEASM- 343/19.www.knov el.com/knov el2/Toc.jsp.

5. Cycon et al., 2006). Cycon M.; Piotrowska-Seget Z.; Kaczynska A.; and Kozdro J.; Microbiological characteristics of a sandy loam soil exposed to tebuconazole and 1-cyhalothrin under laboratory conditions. Ecotoxicology, 2006; 15: 639-646.

6. Dutta M., D.Sarkar, R.Pal and R.R.Kole, 2008. Environ. Monit. Assess 60, 385-391

7. Das A. C. and D. Mukherjee, 2000, Influence of insecticides on microbial transformation of nitrogen and phosphorus in typieorchralf soil. J. Agric. Food Chem., 48:3728-3732

8. Das A.C., A. Chakrabarty, P. Sukul and D. Mukherjee, 1995. Insecticides: Their effect on microorganisms and persistence in rice soil. Microbial. Res., 50:187-194.

9. Digrak M. and F. Kazanici, 2001. Effect of some organophosphorous insecticides on soil microorganisms. Turk. J.Biol., 25:51-58.

10. Komal V, Singh DK, Agarwal HC, Dhawan AK, Dureja P (1999) Effect of repeated pesticide application on soil properties in cotton fields. pp. 325.

11. Lo pez L.; Pozo C.; Go 'mez M. A.; Calvo C.\& Gonza ' les Lo 'pez J., 2002; Studies on the effects of the insecticide aldrin on aquatic microbial populations. Int. Biodeter. Biodegr, 2002; 50; 83-87.

12. A.A. Masum Billah, M.H. Ferdous, T.Taufique, H. Mehraj and A.F.M.Jamaluddin, 2014. Effect of insecticides on soil microorganisms, Int. J. Expt. Agric. 4(4):24-28(November 2014)

13. M.A.Latif et al. (2008) M.A. Latif, M.A. Razzaque and M.M. Rahman, 2008. Impact of Some Selected Insecticides Application on Soil Microbial Respiration. Pakistan Journal of Biological Sciences, 11: 2018-2022.

14. Moumit Roy Goswami, Ujjal Kumar Pati, Ashim Chowdhury and Aniruddha Mukhopadhyay, 2012. Studies on the effect of cypermethrin on soil microbial biomass and its activity in an alluvial soil. International Journal of Agriculture and Food Science 2013, 3(1): 1-9.

15. Nazia Sultan, Bharti S. Raipat and M.P.Sinha, 2010. Effect of organophosphorus insecticide on soil. The Bioscan, An International Quarterly Journal of Life Sciences, Special Issue, Vol.1, 239-246; 2010.

16. Pandey S, Singh D K, 2004. Total bacterial and fungal population after chlorpyrifos and quinalphos treatments in groundnut (ArachishypogaeaL.) soil.Chemosphere, 55(2): 197-205.

17. Purohit S.S., 2003, Microbiology Fundamentals and Application. 6th Edition., Agribios, Chopasani Road, Jodhpur, 342002, India, ISBN: 81-7754-024-6, pp. 15-37.

18. Rao N. S. S.,1995, Soil Microorganisms and Plant Growth. 3rd Edition, Oxford and IBH Publishing Co. Pvt. Ltd.,66 Jan path, New Delhi 110001, India, ISBN: 1-88616-18-5, pp. 26-79.

19. Sonia Sethi, Saksham Gupta, 2013. Impact of Pesticides and Biopesticides on Soil Microbial Biomass Carbon, Universal Journal of Environmental Research and Technology, 2013, Volume 3, Issue 2: 326-330.

20. Sarnaik, S.S., Kanekar, P.P., Raut, V.M., Taware, S.P., Chavan, K.S \& Bhadbhade, B.J., 2006. Effect of application of different pesticides to soybean on the soil microflora. Journal of Environmental Biology, 27(2), 423-426.

21. Jones W. J.; and Ananyeva N. D., 2001; Correlations between pesticide transformation rate and microbial respiration activity in soil of different ecosystems. Biol. Fertil. Soils. 2001; 33: 477-483 